\title{
A comprehensive Monte Carlo study to design a novel multi-nanoparticle loaded nanocomposites for augmentation of attenuation coefficient in the energy range of diagnostic X-rays
}

\author{
Elahe SAYYADI ${ }^{\mathrm{a}}$, Asghar MESBAHIa,, ${ }^{\mathrm{*}}$, Reza Eghdam ZAMIRI ${ }^{\mathrm{b}}$, Farshad Seyyed NEJAD \\ ${ }^{a}$ Medical Radiation Sciences Research Team, Tabriz University of Medical Sciences, Iran \\ ${ }^{b}$ Radio-oncology Department, Shahid Madani Hospital, Tabriz University of Medical Sciences, Medical Radiation Sciences \\ Research Team, Tabriz University of Medical Sciences, Iran \\ *E-mail address: amesbahi2010@gmail.com
}

\begin{abstract}
Introduction: The present study aimed to investigate the radiation protection properties of silicon-based composites doped with nano-sized $\mathrm{Bi}_{2} \mathrm{O}_{3}, \mathrm{PbO}, \mathrm{Sm}_{2} \mathrm{O}_{3}, \mathrm{Gd}_{2} \mathrm{O}_{3}, \mathrm{WO}_{3}$, and $\mathrm{IrO}_{2}$ particles. Radiation shielding properties of $\mathrm{Sm}_{2} \mathrm{O}_{3}$ and $\mathrm{IrO}_{2}$ nanoparticles were investigated for the first time in the current study.

Material and methods: The MCNPX (2.7.0) Monte Carlo code was utilized to calculate the linear attenuation coefficients of single and multi-nano structured composites over the $X$-ray energy range of 10-140 keV. Homogenous distribution of spherical nanoparticles with a diameter of $100 \mathrm{~nm}$ in a silicon rubber matrix was simulated. The narrow beam geometry was used to calculate the photon flux after attenuation by designed nanocomposites.

Results: Based on results obtained for single nanoparticle composites, three combinations of different nano-sized fillers $\mathrm{Sm}_{2} \mathrm{O}_{3}+\mathrm{WO}_{3}+\mathrm{Bi}_{2} \mathrm{O}_{3}, \mathrm{Gd}_{2} \mathrm{O}_{3}+\mathrm{WO}_{3}+\mathrm{Bi}_{2} \mathrm{O}_{3}$, and $\mathrm{Sm}_{2} \mathrm{O}_{3}+\mathrm{WO}_{3}+\mathrm{PbO}$ were selected, and their shielding properties were estimated. In the energy range of 20-60 keV Sm $2 \mathrm{O}_{3}$ and $\mathrm{Gd}_{2} \mathrm{O}_{3}$ nanoparticles, in 70-100 keV energy range $\mathrm{WO}_{3}$ and for photons energy higher than $90 \mathrm{keV}, \mathrm{PbO}$ and $\mathrm{Bi}_{2} \mathrm{O}_{3}$ nanoparticles showed higher attenuation. Despite its higher density, $\mathrm{IrO}_{2}$ had lower attenuation compared to other nanocomposites. The results showed that the nanocomposite containing $\mathrm{Sm}_{2} \mathrm{O}_{3}, \mathrm{WO}_{3}$, and $\mathrm{Bi}_{2} \mathrm{O}_{3}$ nanoparticles provided better shielding among the studied samples.

Conclusions: All studied multi-nanoparticle nanocomposites provided optimum shielding properties and almost $8 \%$ higher attenuation relative to single nano-based composites over a wide range of photon energy used in diagnostic radiology. Application of these new composites is recommended in radiation protection. Further experimental studies are suggested to validate our findings.
\end{abstract}

Key words: nanocomposite; radiation; attenuation coefficient; diagnostic X-rays; MCNPX.

\section{Introduction}

Nowadays, low energy X-ray beams are widely employed in diagnostic radiology including radiography, fluoroscopy, mammography, angiography, and interventional image-guided procedures. On the other hand, due to the dangerous and harmful effects of direct or scattered radiation for personnel and patients, it is essential to optimize the radiation protection regulations and develop effective shielding materials. Therefore, protection against $\mathrm{X}$-ray exposures plays a vital role in the safe usage of $\mathrm{X}$ rays in a clinical environment. ${ }^{1-3}$ The absorption of photons by a thickness of shielding material is simply expressed by the Lambert-Beer law: $I=I_{0} e^{-\mu x}$, where $I_{0}$ and $I$ are the incident and transmitted beam intensities, also $\mathrm{x}$ is the thickness of the attenuator material, and $\mu$ is the linear attenuation coefficient. The selection of the appropriate materials for shielding depends on the radiation source's type, intensity, and energy. The probability of interactions depends on the energy of the incident photon, the atomic number, and the density of the shielding material. ${ }^{4-7}$

Lead aprons are commonly considered protection devices. The high atomic number of lead and its high density enhance its efficiency in the absorption of the radiation. In contrast, prolonged use of these types of protectors due to their heaviness leads to physical fatigue and back strain and may compromise the performance of radiologists and technologists. Toxicity and easily cracking are the other disadvantages of lead garments. Most recent studies focused on lightweight and strong non-lead composite materials to guarantee the safe usage of protective aprons and devices. ${ }^{\mathbf{8}-10}$

Polymer composites are strong, lightweight, and comfortable. They have shown favorable mechanical performance, heat

(C) 2021 Elahe Sayyadi, Asghar Mesbahi, Reza Eghdam Zamiri, Farshad Seyyed Nejad. This is an open access article licensed under the Creative Commons Attribution-NonCommercial-NoDerivs License (http://creativecommons.org/licenses/by-nc-nd/4.0/). 
resistance, and are capable of absorbing radiation more effective. Various polymers such as polyethylene, silicon, and epoxy resin are used as a matrix bed in these composites, and various metallic elements can be used as fillers. Recently, metallic fillers in micro and nano scales have been employed in the composition of new shielding composites. Studies have revealed that nanoparticles exhibit unique physical and chemical properties in micro and macro dimensions compared to the same material. Besides, nanomaterials have a higher surface-tovolume ratio and higher photon absorption in the low energy range. ${ }^{11-13}$

Various studies have been done to examine the properties of protective compounds with different elements and $\mathrm{K}$ - absorption edge energies, such as $\mathrm{Cu}, \mathrm{Sn}, \mathrm{Ba}, \mathrm{W}, \mathrm{Sb}, \mathrm{Y}, \mathrm{Pb}, \mathrm{Gd}$, and $\mathrm{Zr}$. The nanomaterials used in previous studies have properties such as high density and a suitable K-absorption edge for the used photon energy. Among the studied atoms, elements such as tungsten $\mathrm{Z}=74$ and bismuth $\mathrm{Z}=83$, which have lower toxicity and are inexpensive, can be considered as a replacement for toxic $\mathrm{Pb}$ and provide better attenuation in the energy range of 70-90 keV. ${ }^{\mathbf{1 4 - 1 6}}$

There are enormous articles on the use of nanoparticles for radiation shielding. ${ }^{17} \mathrm{~A}$ study showed that a sheet with a thickness of $1 \mathrm{~cm}$ made of epoxy- $\mathrm{Gd}_{2} \mathrm{O}_{3}$ nanocomposite was able to absorb 50-70\% of X-rays in the energy range of 40-100 $\mathrm{kVp}$. In another experimental study, a composite shield containing $\mathrm{Gd}_{2} \mathrm{O}_{3}$ nanomaterial fillers with thicknesses of 8 to $16 \mathrm{~mm}$ provided all degrees of X-ray protection needed in the clinic and also improved the mechanical and fracture toughness of the epoxy resin. ${ }^{18,19}$ According to the results obtained by Verdipour et al. the mass attenuation coefficient of $\mathrm{WO}_{3}, \mathrm{Bi}_{2} \mathrm{O}_{3}$, and $\mathrm{PbO}$ nanoparticles was $17 \%$ higher compared to their microparticles in silicon resin and $\mathrm{PbO}$ and $\mathrm{Bi}_{2} \mathrm{O}_{3}$ nanoparticles provided better absorption compared to $\mathrm{WO}_{3}{ }^{20}$ Furthermore, the researchers showed that the samarium incorporated into carbon fiber improved the performance of gamma radiation and neutron shielding. ${ }^{21}$ In an experimental study, EPVC composites containing micro and nano-powders of bismuth $\left(\mathrm{Bi}_{2} \mathrm{O}_{3}\right)$, lead $(\mathrm{PbO})$, and tungsten $\left(\mathrm{WO}_{3}\right)$ were compared for photons with the tube voltages of $40-100 \mathrm{kVp}$. Composites containing bismuth nanoparticles or lead oxide microparticles showed the most efficient attenuation. It was concluded that the $\mathrm{Bi}_{2} \mathrm{O}_{3}$ nano-sized particles can be an appropriate alternative to $\mathrm{PbO}$ in the fabrication of shielding composites. ${ }^{15}$

The attenuation and interaction of different elements with $\mathrm{X}$ ray through photoelectric effect depend strongly on the proximity of photon energy and the K-electrons' binding energy. When the energy of photons becomes slightly higher than the Kabsorption edge energy of electrons, the absorption of photons increases remarkably. Indeed, the attenuation coefficient of elements rises at their $\mathrm{K}$ - absorption edge and exhibits an intense peak then declines exponentially with an increase in photon energy. Regarding the variation in K- absorption edge energy for individual elements, choosing a material to maintain protection over a particular energy range can be challenging. In addition to the materials studied in previous publications, other potential elements were examined in the present study. Elements such as lead, bismuth, tungsten, and gadolinium have been used in previous studies. On the other hand, iridium and samarium have not been studied in any other investigation for X-ray shielding in the diagnostic energy range.

The authors of the current work think that if several types of nanoparticles with different $\mathrm{K}$ - absorption edges are applied in the composition of new composites which we will name multinanoparticle composites (MNC) in this article, it may provide better protection over a wide range of photon energy used in diagnostic radiology, i.e., 40-140 keV. Therefore, the current study aimed to investigate whether composites made of different elements with different $\mathrm{K}$ - absorption edges would be more effective than single-nanoparticle composites and would create stronger attenuation in the wide range of photon energies applied in diagnostic radiology. The linear attenuation coefficients of all samples composed of single nanoparticles were calculated by using Monte Carlo (MC) method and compared. Then, some MNC compositions were derived from results, and their shielding properties were tested and compared. Finally, several MNCs composed of different elements were examined, and the most effective composition was introduced as a novel MNC for shielding purposes in diagnostic radiology.

\section{Materials and methods}

\section{Monte Carlo simulation model}

In this study, the MCNPX MC code (version.2.7.0) was used for the simulation. MCNPX is a three-dimensional N-particle radiation transport code. It is utilized to calculate the transport, modeling, and analysis of the interaction of neutrons, protons, photons and electrons with materials. In this study, to reduce the statistical errors and MC runtime, all calculations were done in the photon mode and the importance of electrons was considered zero in all cells. The narrow beam geometry including source, collimators, and detector was modeled and are shown in Figure 1. The source was defined as a surface source with a radius of $5 \mathrm{~mm}$, placed in a hole with a radius of $1 \mathrm{~cm}$ and length of $5 \mathrm{~cm}$ inside the first lead cylinder, and emitted parallel photons. The collimators were two lead cylinders with a radius of $20 \mathrm{~cm}$ and a length of $20 \mathrm{~cm}$ to remove the scattered beams and satisfy narrow beam geometry conditions. The detector was defined in a hole with a radius of $1 \mathrm{~cm}$ and a length of $5 \mathrm{~cm}$ in the second lead cylinder. They were defined at a distance of 40 $\mathrm{cm}$ from the nanocomposite shield. In other words, the shielding material placed between lead cylinders and the distance from each cylinder was $40 \mathrm{~cm}$. Only the primary photons reached the detector after passing through the shield. The shielding material consisted of silicon rubber as a matrix was doped with different nanoparticles. We used the lattice (LAT) and universe (U) cards to define matrix and fillers as seen in Figure 1. 

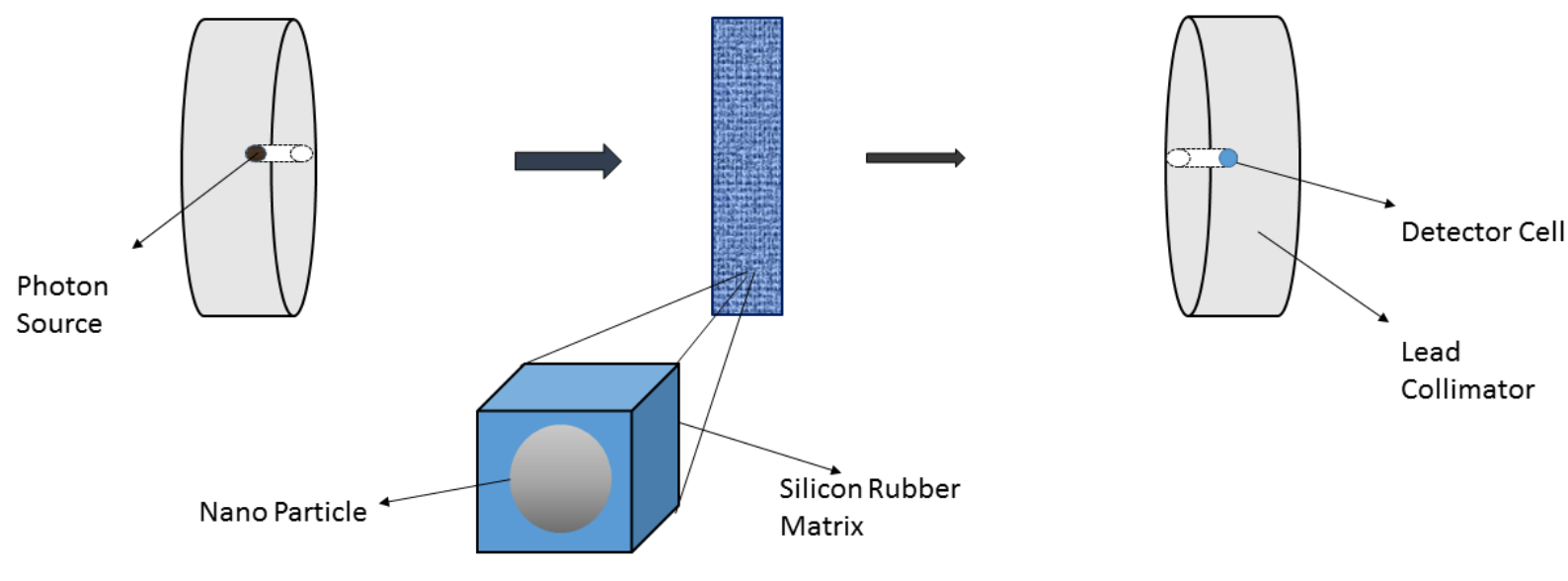

Latice universe Cards

Figure 1. A schematic representation of the simulated narrow beam geometry and lattice-universe arrangement for the silicon rubber matrix filled with nanoparticles.

\section{Nanoparticles designation in MCNPX code}

The nano-sized fillers selected for this study included iridium (Ir, $\mathrm{K}=76.11 \mathrm{keV})$, lead $(\mathrm{Pb}, \mathrm{K}=88 \mathrm{keV})$, tungsten (W, $\mathrm{K}=69.5 \mathrm{keV})$, gadolinium $(\mathrm{Gd}, \mathrm{K}=50.2 \mathrm{keV})$, bismuth ( $\mathrm{Bi}$, $\mathrm{K}=90.5 \mathrm{keV})$ and samarium $(\mathrm{Sm}, \mathrm{K}=46.83 \mathrm{keV})$. These particles have a relatively high atomic number and density. Therefore, we tested these nanoparticles and investigated their performance as shielding nanocomposites individually and as MNC samples in the $10-140 \mathrm{keV}$ energy range. The attenuation coefficient of the above-mentioned nanoparticles was calculated by using the Monte Carlo method.

The silicon rubber with the elemental composition of $\mathrm{SiO}_{2}\left(\mathrm{CH}_{3}\right)$ and the density of $1.05 \mathrm{~g} / \mathrm{cm}^{3}$ was considered as the matrix of the composite. The silicon rubber was divided into cubic cells or voxels. Each nanoparticle was situated as a sphere with a diameter of $100 \mathrm{~nm}$ in the center of voxels. The nano fillers consisted of $\mathrm{WO}_{3}, \mathrm{PbO}, \mathrm{Gd}_{2} \mathrm{O}_{3}, \mathrm{Sm}_{2} \mathrm{O}_{3}, \mathrm{IrO}_{2}$, and $\mathrm{Bi}_{2} \mathrm{O}_{3}$ used in this investigation.

\section{The linear attenuation coefficient calculations}

The linear attenuation coefficient was calculated for each single nano-based composite. To make the calculations and data more accurate, at least six different thicknesses were used. For this purpose, in each MC simulation; photon transmittance was calculated for thicknesses of 0.2-1.2 mm of each sample, and then the transmittance-thickness curve was obtained for each sample. The concentration of each nano-sized filler was $30 \mathrm{wt} \%$ of silicon matrix. The used X-ray energy was from 10 to 140 $\mathrm{keV}$ in the radiology range with ten steps. For calculation of photon flux inside the detector cell, the F4 tally of MCNPX was used in terms of $\mathrm{n} / \mathrm{cm}^{2}$. The fluencies of detected photons with different thicknesses of shielding materials were used to acquire transmittance-thickness semilog curves. The linear attenuation coefficient was derived from the obtained curve. The gradient of the obtained linear descending curve was linear attenuation coefficient of each sample. The runtime of MC simulations was $1 \mathrm{~h}$ on a pc system. The statistical errors of MC results were less than $1 \%$ on average for all simulations. In the next step, some MNCs were designed based on the superimposition of $\mathrm{K}$ absorption edge energy of individual nanoparticles in different energy of photons.

Each sample contained silicon rubber as a matrix and nano oxides as fillers. Fillers were selected based on better attenuation in each energy range obtained in the first step for single-particle composites. In other words, the logic for their selection was that in the diagnostic radiology a continuous spectrum of photons is used. Thus, to have more efficient shielding, a composite composed of multiple different nanoparticles with K- absorption edges located in the different part of photon spectrum would be more effective. The selected nano-sized fillers for MNC samples included: (1) $\mathrm{Sm}_{2} \mathrm{O}_{3}+\mathrm{WO}_{3}+\mathrm{PbO}$ (2) $\mathrm{Sm}_{2} \mathrm{O}_{3}+\mathrm{WO}_{3}+\mathrm{Bi}_{2} \mathrm{O}_{3}$ (3) $\mathrm{Gd}_{2} \mathrm{O}_{3}+\mathrm{WO}_{3}+\mathrm{Bi}_{2} \mathrm{O}_{3}$.

The total concentration of selected fillers in MNC composition was $30 \mathrm{wt} \%$ of silicon rubber. Then, the transmission of photons $\left(\mathrm{n} / \mathrm{cm}^{2}\right)$ was calculated for all MNC samples. To evaluate the radiation protection efficiency of studied MNC samples, their attenuation rates were compared with $0.25 \mathrm{~mm} \mathrm{~Pb}$ in the energy range of 10-140. The thicknesses of single and multiple nanostructured composites were considered $1 \mathrm{~mm}$. The MNC samples were examined also for the spectral CT energy spectra for $140 \mathrm{kVp}$ and their transmission rates were compared to each other. 


\section{Results}

\section{Validation of the simulation narrow beam geometry}

In the present study, the simulated narrow beam geometry was verified according to the data provided by the WinXCom software. ${ }^{\mathbf{2 2 , 2 3}}$ For this aim, the linear attenuation coefficients of lead $\left(\right.$ density $\left.=11.35 \mathrm{~g} / \mathrm{cm}^{3}\right)$, bismuth $\left(\right.$ density $\left.=9.78 \mathrm{~g} / \mathrm{cm}^{3}\right)$, and the silicon rubber (density $=1.05 \mathrm{~g} / \mathrm{cm}^{3}$ ) at the photon energies of 50, 100 and $150 \mathrm{keV}$ were calculated by MC model then were compared with WinXCom. The results of benchmarking of the MC model are presented in Table $\mathbf{1 .}$

As it can be seen, a maximum difference of $0.6 \%$ was found between MC and WinXCom values. Hence, the MC model was validated. The difference was calculated according to the following equation:

$\operatorname{Difference}(\%)=\frac{\mu_{M C}-\mu_{W i n x}}{\mu_{W i n x}} \times 100$

Eq. 1

\section{Effect of nanomaterial concentration on nanocomposite attenuation}

All nanomaterials were loaded inside the silicon rubber matrix in concentrations of 5, 15, and 30\%. The linear attenuation coefficients were calculated for the aforementioned nanocomposites to investigate the effect of nanomaterials concentration. The obtained results are illustrated in Figure 2 (next page). It can be deduced from Figure 2, the increase in the concentration of nanoparticles leads to a greater attenuation coefficient for all studied nanocomposites.

Results of MCNPX code for linear attenuation coefficient for each nano-based composite are given in Figure 3 (next page). As it can be seen, the silicon rubber sample without nanomaterial fillers had the minimum attenuation. Also, $100 \mathrm{wt} \%$ nanoparticle samples showed maximum attenuation. In the middle part, the linear attenuation coefficients of nanocomposites composed of $70 \mathrm{wt} \%$ silicon rubber and $30 \mathrm{wt} \%$ fillers including $\mathrm{Bi}_{2} \mathrm{O}_{3}, \mathrm{PbO}$, $\mathrm{IrO}_{2}, \mathrm{WO}_{3}, \mathrm{Gd}_{2} \mathrm{O}_{3}$, and $\mathrm{Sm}_{2} \mathrm{O}_{3}$ in terms of photon energy (keV) are shown. The attenuation coefficient of each nanocomposite and pure silicon rubber in the energy range of 10-40 keV showed no significant difference. However, after $40 \mathrm{keV}$, nano-based composites provided superior attenuation relative to pure silicon rubber.

\section{Effect of different K- absorption edge energy on linear attenuation coefficients}

The calculated attenuation coefficients for $30 \%$ concentration by MC model for all samples were compared and presented in Figure 4.

Figure 4 indicates that in the energy range of 10 to $20 \mathrm{keV}$, the behaviours of all samples were almost the same. In the range of 20-30 keV, nanofillers of $\mathrm{Sm}_{2} \mathrm{O}_{3}$ and $\mathrm{Gd}_{2} \mathrm{O}_{3}$ had a higher attenuation coefficient. In the range of $30-50 \mathrm{keV}, \mathrm{WO}_{3}$ was higher than other nanoparticles. In the energy range of 50-60 $\mathrm{keV}, \mathrm{Sm}_{2} \mathrm{O}_{3}$, and, $60-70 \mathrm{keV}$, nano $\mathrm{Gd}_{2} \mathrm{O}_{3}$ particles, and in the energy range of 70-100 keV, tungsten nanofillers had higher attenuation. $\mathrm{PbO}$ had a peak at $90 \mathrm{keV}$. For photons higher than $100 \mathrm{keV}, \mathrm{Bi}_{2} \mathrm{O}_{3}$ and $\mathrm{PbO}$ had better attenuation. On the other hand, the attenuation provided by $\mathrm{IrO}_{2}$ nanocomposite, despite its higher density, was lower than other nanostructured composites.

Table 1. Comparison of the linear attenuation coefficients of $\mathrm{Pb}, \mathrm{Bi}$, and Silicon rubber calculated by the MC model with WinXcom.

\begin{tabular}{ccccc}
\hline \hline Energy(keV) & Samples & MCNPX & WinXCom & Difference \% \\
\hline \multirow{2}{*}{50} & $\mathrm{~Pb}$ & 90.69 & 91.18 & 0.54 \\
& $\mathrm{Bi}$ & 81.68 & 81.94 & 0.32 \\
& $\mathrm{Silicon}$ & 0.35 & 0.31 & 0.11 \\
\hline \multirow{3}{*}{100} & $\mathrm{~Pb}$ & 62.79 & 62.92 & 0.2 \\
& $\mathrm{Bi}$ & 55.8 & 56.12 & 0.58 \\
& $\mathrm{Silicon}$ & 0.1788 & 0.17955 & 0.00417 \\
\hline \multirow{2}{*}{150} & $\mathrm{~Pb}$ & 22.731 & 22.83 & 0.47 \\
& $\mathrm{Bi}$ & 20.251 & 20.36 & 0.54 \\
& $\mathrm{Silicon}$ & 0.1478 & 0.1512 & 0.0238 \\
\hline \hline
\end{tabular}

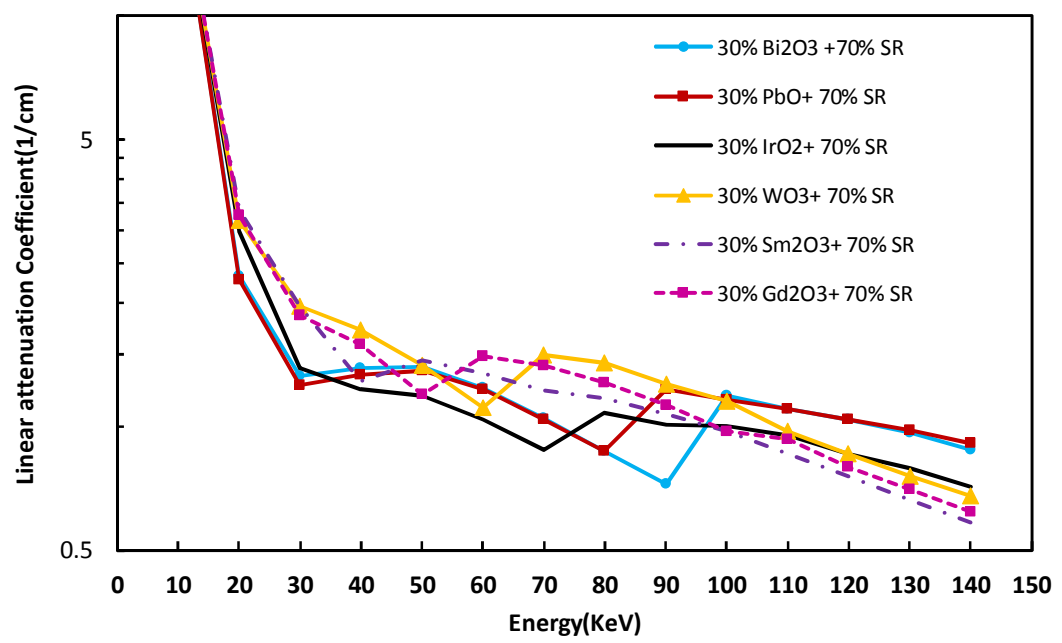

Figure 4. The comparison of linear attenuation coefficients for nanocomposites of $\mathrm{Bi}_{2} \mathrm{O}_{3}, \mathrm{WO}_{3}, \mathrm{Gd}_{2} \mathrm{O}_{3}, \mathrm{Sm}_{2} \mathrm{O}_{3}, \mathrm{IrO}_{\text {, and }} \mathrm{PbO}_{\text {. }}$ 

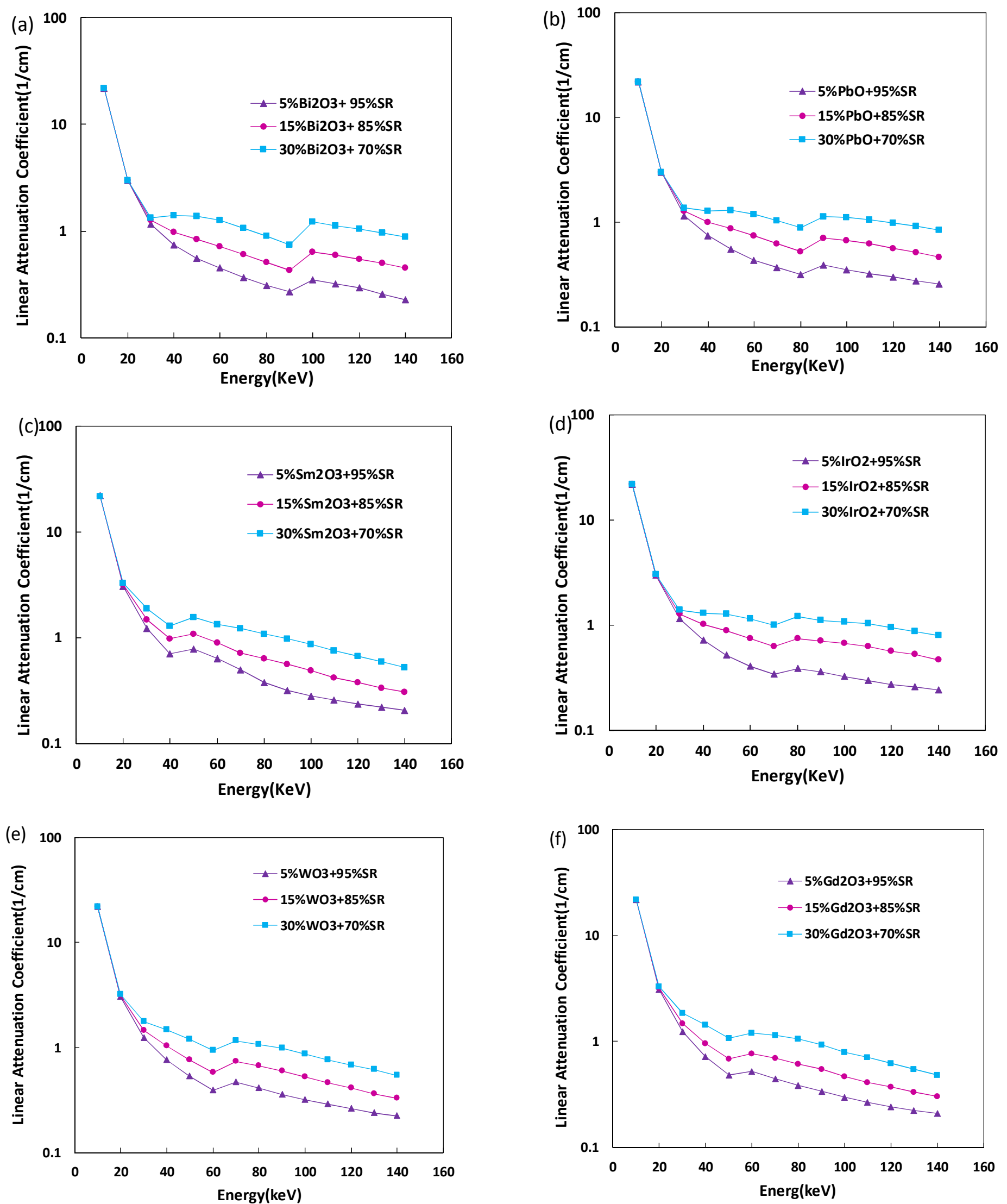

Figure 2. The comparison of linear attenuation coefficients for the studied nanocomposites at the concentrations of $5,15,30 \%$ a) $\mathrm{Bi}_{2} \mathrm{O}_{3}$, b) $\mathrm{PbO}$, c) $\mathrm{Sm}_{2} \mathrm{O}_{3}$, d) $\mathrm{IrO}_{2}$ e) $\mathrm{WO}_{3}$, f) $\mathrm{Gd}_{2} \mathrm{O}_{3}$ 

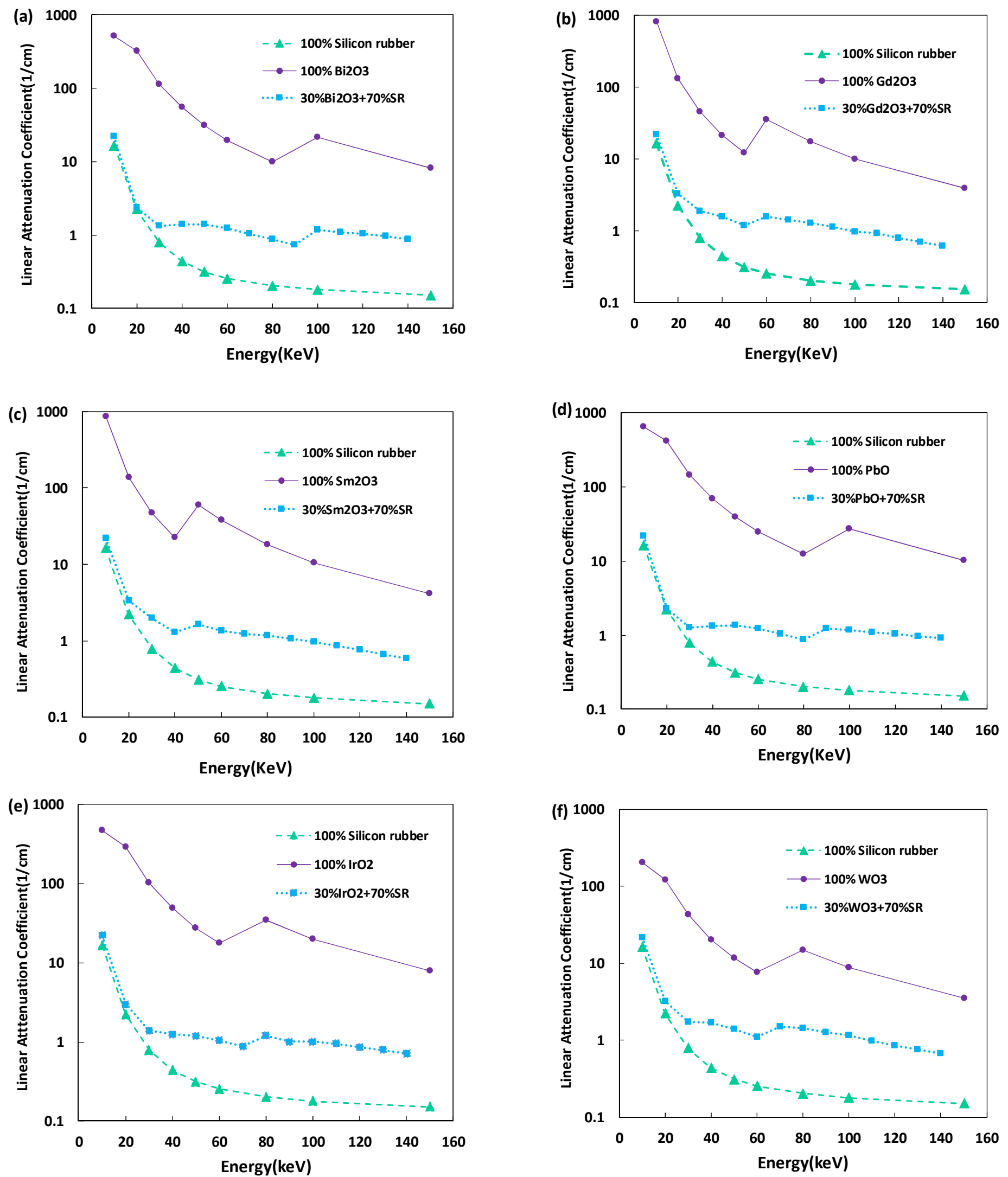

Figure 3. The comparison of the linear attenuation coefficients of pure silicon rubber with different nanocomposites: a) $30 \% \mathrm{Bi}_{2} \mathrm{O}_{3}+70 \%$ Silicon and $100 \% \mathrm{Bi}_{2} \mathrm{O}_{3}$ b) $30 \% \mathrm{Gd}_{2} \mathrm{O}_{3}+70 \%$ Silicon and $100 \% \mathrm{Gd}_{2} \mathrm{O}_{3}$ c) $30 \% \mathrm{Sm}_{2} \mathrm{O}_{3}+70 \%$ Silicon and $100 \% \mathrm{Sm}_{2} \mathrm{O}_{3}$ d) $30 \% \mathrm{PbO}+70 \% \mathrm{Silicon}$ and $100 \% \mathrm{PbO}$, e) $30 \% \mathrm{IrO}_{2}+70 \%$ Silicon and $100 \% \mathrm{IrO}_{2}$, f) $30 \% \mathrm{WO}_{3}+70 \%$ Silicon and $100 \%$ WO 

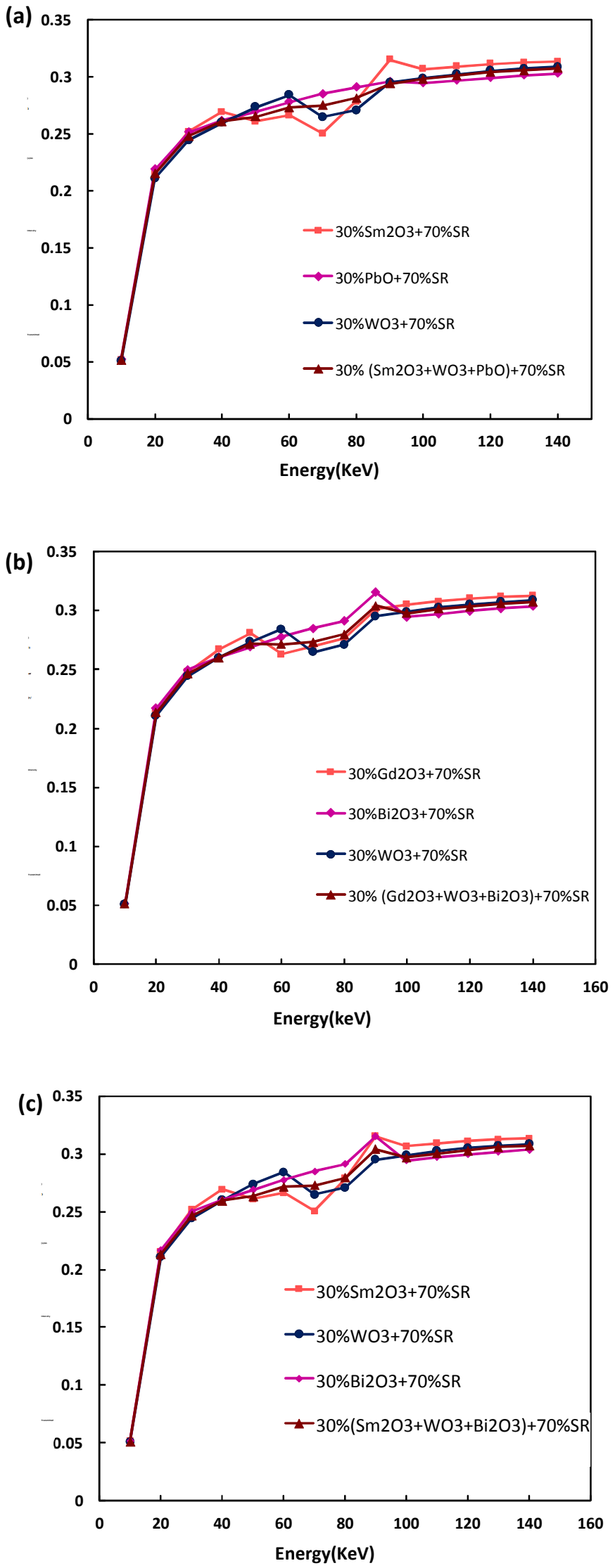

Figure 5. The comparison of transmitted intensity from the thickness of $1 \mathrm{~mm}$ of nanocomposites composed of a single nanoparticle and $\mathbf{7 0 \%}$ Silicon rubber with multi-nanoparticle composites
Based on obtained results, samarium, gadolinium, tungsten, bismuth, and lead nano-oxides were selected for designation of new MNCs. Three compositions that produced higher attenuation in the whole range of photon energy were selected including, (1) $\mathrm{Sm}_{2} \mathrm{O}_{3}+\mathrm{WO}_{3}+\mathrm{PbO}$ (2) $\mathrm{Sm}_{2} \mathrm{O}_{3}+\mathrm{WO}_{3}+\mathrm{Bi}_{2} \mathrm{O}_{3}$ (3) $\mathrm{Gd}_{2} \mathrm{O}_{3}+\mathrm{WO}_{3}+\mathrm{Bi}_{2} \mathrm{O}_{3}$. The results are depicted in Figure 5.

In Figure 5a the results show that the transmitted intensity of MNC in the energy range of 10 to $50 \mathrm{keV}$ was overall $3.5 \%$ lower than $\mathrm{PbO}$ and $\mathrm{Sm}_{2} \mathrm{O}_{3}$ nano- based composites. In the energy range of 50 to $70 \mathrm{keV}$, the MNC sample provided 5\% higher attenuation than $\mathrm{WO}_{3}$ and $\mathrm{PbO}$ composites. In the 70 to $80 \mathrm{keV}$ energy range, the MNC absorbed photons $4 \%$ more than lead nanocomposite. For $90 \mathrm{keV}$, the sample had the minimum transmission in comparison with other nanostructured composites. The maximum percentage difference was $7 \%$ for 90 $\mathrm{keV}$ between $\mathrm{Sm}_{2} \mathrm{O}_{3}$ and the MNC sample. After $100 \mathrm{keV}$, the MNC sample attenuated the $\mathrm{X}$-ray beams more than $\mathrm{WO}_{3}$ and $\mathrm{Sm}_{2} \mathrm{O}_{3}$ nano-based composites. In other energy ranges, the obtained superiority was lower than $4 \%$. This figure also indicates that single-nanoparticle nanocomposites had their best performance only in their K-absorption edge energy, while the MNC nanocomposite supplied more effective attenuation properties over the entire radiology energy range.

In Figure 5b, the transmitted intensity of the $\mathrm{MNC}$ in the energy range of 10 to $50 \mathrm{keV}$ was almost $3 \%$ lower than $\mathrm{Bi}_{2} \mathrm{O}_{3}$ and $\mathrm{Gd}_{2} \mathrm{O}_{3}$ nanostructured composites. In the energy range of 50 to $70 \mathrm{keV}$, the attenuation capability of the MNC sample was $7 \%$ more than $\mathrm{WO}_{3}$ and $\mathrm{Bi}_{2} \mathrm{O}_{3}$ composites. In the 70 to $100 \mathrm{keV}$ energy range, the MNC absorbed photons almost $5 \%$ better than nano-bismuth composite. The maximum difference was overall $7 \%$ in $60 \mathrm{keV}$ between $\mathrm{WO}_{3}$ and MNC. After $100 \mathrm{keV}$ the MNC sample provided superior attenuation of the $\mathrm{X}$-ray beams compared to $\mathrm{WO}_{3}$ and $\mathrm{Gd}_{2} \mathrm{O}_{3}$ single nanocomposites. In other energy ranges, the obtained discrepancies were lower than $3 \%$.

In Figure 5c The transmitted intensity of MNC in the energy range of 10 to $50 \mathrm{keV}$ was overall $4 \%$ lower than the composites doped with nano- $\mathrm{Bi}_{2} \mathrm{O}_{3}$ and nano- $\mathrm{Sm}_{2} \mathrm{O}_{3}$. In the energy range of 50 to $70 \mathrm{keV}$ the MNC sample shielded photons $8 \%$ more than $\mathrm{WO}_{3}$ and $\mathrm{Bi}_{2} \mathrm{O}_{3}$ composites. In the 70 to $100 \mathrm{keV}$ energy range, the $\mathrm{MNC}$ absorbed photons almost $6 \%$ more than $\mathrm{Bi}_{2} \mathrm{O}_{3}$. The maximum overall percentage difference was $8 \%$ in $70 \mathrm{keV}$ between $\mathrm{Bi}_{2} \mathrm{O}_{3}$ and $\mathrm{MNC}$. After $100 \mathrm{keV}$, the MNC sample shielded the X-ray beams more efficiently than $\mathrm{WO}_{3}$ and $\mathrm{Sm}_{2} \mathrm{O}_{3}$ nano-based composites. In other energy ranges, the obtained discrepancies were lower than $5 \%$.

a) $30 \% \mathrm{Sm}_{2} \mathrm{O}_{3}, 30 \% \mathrm{WO}_{3}, 30 \% \mathrm{PbO}$ and multiple nanocomposite of $\mathrm{Sm}_{2} \mathrm{O}_{3}+\mathrm{WO}_{3}+\mathrm{PbO}$

b) $30 \% \mathrm{Gd}_{2} \mathrm{O}_{3}, 30 \% \mathrm{WO}_{3}, 30 \% \mathrm{Bi}_{2} \mathrm{O}_{3}$ and multiple nanocomposite of $\mathrm{Sm}_{2} \mathrm{O}_{3}+\mathrm{WO}_{3}+\mathrm{Bi}_{2} \mathrm{O}_{3}$

c) $30 \% \mathrm{Sm}_{2} \mathrm{O}_{3}, 30 \% \mathrm{WO}_{3}, 30 \%, \mathrm{Bi}_{2} \mathrm{O}_{3}$ and multiple nanocomposite of $\mathrm{Gd}_{2} \mathrm{O}_{3}+\mathrm{WO}_{3}+\mathrm{Bi}_{2} \mathrm{O}_{3}$ 
In Figure 6, the attenuations of the selected MNCs were compared to $0.25 \mathrm{~mm}$ of pure $\mathrm{Pb}$. For the pure $\mathrm{Pb}$, an abrupt falloff is evident in the energy of about $88 \mathrm{keV}$ due to its k-edge binding energy. In other words, at the k-edge binding energy, the probability of photoelectric interaction of photons with kelectrons increases significantly and leads to lower transmission of photons from the shielding layer. According to our calculations, for the energy range of 40-140 keV, $5 \mathrm{~mm}$ of our MNCs were equivalent to $0.25 \mathrm{~mm} \mathrm{~Pb}$. Furthermore, among all the MNC samples, the nanocomposite containing $\mathrm{Sm}_{2} \mathrm{O}_{3}, \mathrm{WO}_{3}$ and $\mathrm{PbO}$ in the energy range of 80 to 100 was the most efficient sample. In the energy range of 40 to $80 \mathrm{keV}$ and 100 to $140 \mathrm{keV}$, the sample containing $\mathrm{Sm}_{2} \mathrm{O}_{3}, \mathrm{WO}_{3}$ and $\mathrm{Bi}_{2} \mathrm{O}_{3}$ had the maximum attenuation. In addition to the mono-energetic mode, the MNC samples were also examined against the photon spectrum of a CT machine with the peak tube voltage of $140 \mathrm{kVp}$. The output is tabulated in Table 2. As it can be deduced from Table 2, there was no significant difference between all the MNC samples in attenuation of the photon energy spectrum of X-ray CT. However, the Sample with $\mathrm{Bi}_{2} \mathrm{O}_{3}$ nanoparticles attenuated the $\mathrm{X}$ ray beam slightly higher than others.

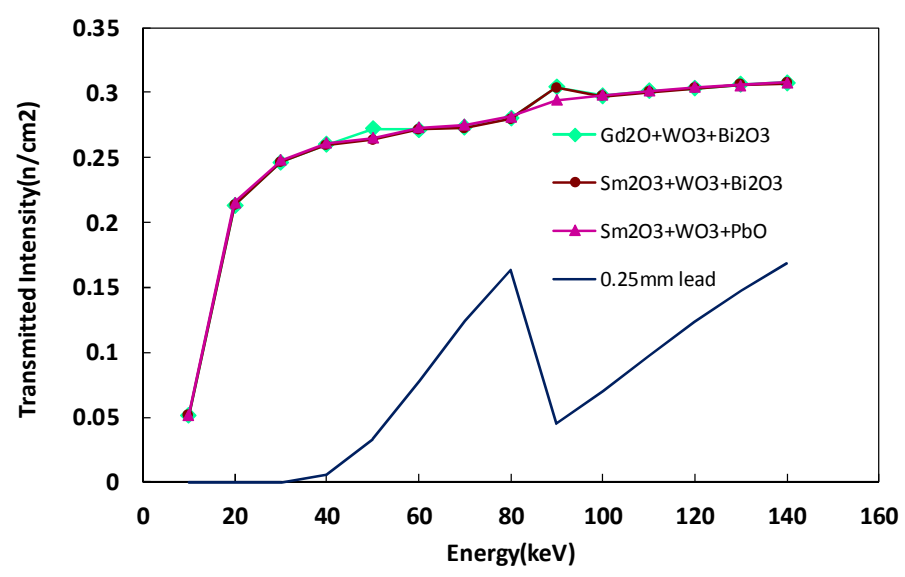

Figure 6. A comparison of transmitted intensity $\left(\mathbf{n} / \mathrm{cm}^{2}\right)$ for multinanoparticle nanocomposites with thickness of $1 \mathrm{~mm}$ and $0.25 \mathrm{~mm}$ of $\mathbf{P b}$.

Table 2. The X-ray transmission intensity of photons for the selected multi-nanoparticle composites in an $x$-ray CT energy spectrum.

\begin{tabular}{cc}
\hline \hline Nanocomposites & $\begin{array}{c}\text { Transmitted intensity }\left(\mathbf{n} / \mathbf{c m}^{2}\right) \\
\text { per initial photon }\end{array}$ \\
\hline $\mathrm{Gd}_{2} \mathrm{O}_{3}+\mathrm{WO}_{3}+\mathrm{Bi}_{2} \mathrm{O}_{3}$ & $2.75 \mathrm{E}-01$ \\
$\mathrm{Sm}_{2} \mathrm{O}_{3}+\mathrm{WO}_{3}+\mathrm{Bi}_{2} \mathrm{O}_{3}$ & $2.74 \mathrm{E}-01$ \\
$\mathrm{Sm}_{2} \mathrm{O}_{3}+\mathrm{WO}_{3}+\mathrm{PbO}$ & $2.76 \mathrm{E}-01$ \\
\hline \hline
\end{tabular}

\section{Discussion}

Most recent investigations have shown that the incorporation of nanomaterials within polymer-based composites can absorb and attenuate radiation more efficiently. In this study we investigated shielding properties of single and MNCs by MC simulation. In order to verify the narrow beam geometry of the MC model and show the reliability of obtained results, the differences between MC and WinXCom results must be as low as $1 \%$. The maximum percentage differences obtained at a photon energy of $50 \mathrm{keV}$ was $0.54 \%$ for lead and at a photon energy of $100 \mathrm{keV}$ was $0.58 \%$ error for bismuth. At photon energy of 50,100, and $150 \mathrm{keV}$ percentage differences were less than $0.6 \%$ for lead, bismuth, and silicon rubber. Due to the interactions of low energy photons with high atomic number materials such as our used nanoparticles, the photoelectric effect becomes the predominant phenomenon, so with the increase in the concentration of fillers, attenuation increases proportionately. In other words, the number of high atomic atoms in the pathway of photons increases directly with an increase in the concentration of the filler. In addition to the nanoparticles used in the previous studies, we also examined the effect of $\mathrm{Sm}_{2} \mathrm{O}_{3}$ and $\mathrm{IrO}_{2}$. An evident increase was observed in attenuation coefficients of all nanoparticles in the vicinity of their $\mathrm{K}$ - absorption edges. $\mathrm{Sm}_{2} \mathrm{O}_{3}$ had good performance in 40 $70 \mathrm{keV}$. In 70-90 keV and up to $100 \mathrm{keV}, \mathrm{WO}_{3}$ and $\mathrm{Bi}_{2} \mathrm{O}_{3}$ had better shielding efficiency. The MNC sample containing $\mathrm{Sm}_{2} \mathrm{O}_{3}$, $\mathrm{WO}_{3}$ and $\mathrm{Bi}_{2} \mathrm{O}_{3}$ provided higher protection compared to other MNCs.

On the other hand, due to economic reasons and availability of $\mathrm{Gd}$ to $\mathrm{Sm}$, the MNC sample include $\mathrm{Gd}_{2} \mathrm{O}_{3}, \mathrm{WO}_{3}$ and $\mathrm{Bi}_{2} \mathrm{O}_{3}$ can be introduced as a cost-effective composite than other multiple samples. The MNC samples were investigated in spectral CT energy too. The composite samples containing $\mathrm{Sm}_{2} \mathrm{O}_{3}+\mathrm{WO}_{3}+\mathrm{Bi}_{2} \mathrm{O}_{3}$ and $\mathrm{Gd}_{2} \mathrm{O}_{3}+\mathrm{WO}_{3}+\mathrm{Bi}_{2} \mathrm{O}_{3}$ nano-sized particles had higher attenuation. Using appropriate composite materials with different $\mathrm{K}$ - absorption edges provides dominance of photoelectric effect to Compton scattering in beams absorption and leads to a reduction in weight with equivalent protection. Indeed, X-rays would be absorbed several times by multiple $\mathrm{K}$ - absorption edges.

According to our results and Dong et al. findings, the attenuation coefficient of the composites doped with nano- $\mathrm{WO}_{3}$ had an increase in the energy range of $69.5 \mathrm{keV}$, which is due to the specific absorption at the $\mathrm{K}$ - absorption edge energy of $\mathrm{WO}_{3}$ and increases the protective properties of the shield. ${ }^{24}$ Our obtained results demonstrate that adding $\mathrm{Bi}_{2} \mathrm{O}_{3}$ and $\mathrm{WO}_{3}$ to nano-based composites leads to better attenuation, in agreement with previous studies. For instance, Nambiar et al., in an experimental study, investigated the X-ray absorption by polymer nanocomposites for protection in IVR and diagnostic categories. PDMS nano-polymers with different concentrations of bismuth oxide as fillers were considered. To achieve the amount of absorption that occurs in lead aprons, a more 
thickness of nanostructured composites was required, so that the thickness of $0.25 \mathrm{~mm}$ of pure lead was equivalent to $3.73 \mathrm{~mm}$ of bismuth oxide (44.44 wt \%). ${ }^{25}$

Our results were in close agreement with an experimental study that designed a nanocomposite shield containing tungsten and bismuth oxide. The prepared samples of $18.75 \mathrm{wt} \% \mathrm{Bi}_{2} \mathrm{O}_{3}$ and $18.75 \mathrm{wt} \% \mathrm{~W}$ had the lowest HVL and better shielding performance. Moreover, the multiple shields had an acceptable attenuation over a wide energy range because of the several absorption edges. However, single nanoparticle composites had higher absorption in a limited energy range. ${ }^{\mathbf{2 6}}$

In previously published studies, the linear attenuation coefficient was calculated for $\mathrm{Bi}_{2} \mathrm{O}_{3}$ and $\mathrm{PbO}$ and their mixtures. The multiple nanocomposites were the most effective sample that was similar to our obtained results. Ozdemir and et al. designed a plastic-based protective material with a flexible nature that protects patients and staff in radiant environments, using EPDM as a matrix for lead oxide nanoparticles as filler. Lead nanoparticles with concentrations of 1, 5, 10, 15, and 20\% were considered and irradiated. Also, nanocomposites containing a mixture of bismuth 20,30,40 wt $\%$ and $20 \mathrm{wt} \%$ lead nanofillers were irradiated too. The sample with $20 \%$ lead oxide and $40 \%$ bismuth oxide in a thickness of $6 \mathrm{~mm}$ had a $99.4 \%$ attenuation coefficient and maximum $\mathrm{Pb}$ equivalent thickness $(0.65 \mathrm{~mm}) .^{27}$ Moreover, our results were consistent with previously published results of Sonsilphong et al., who exhibited lower transmission in 70-90 keV for double layer W/Bi sheet, which is blind absorption zone for lead. $0.4 \mathrm{~mm}$ of this sheet with an equal thickness ratio of $\mathrm{W}$ and $\mathrm{Bi}$ in 70-90 keV showed the same attenuation of $0.5 \mathrm{~mm} \mathrm{~Pb}$. The designed double-layer shield was $36 \%$ lighter than the standard $0.5 \mathrm{~mm} \mathrm{~Pb}$ sheet. ${ }^{28}$ In another study, seven shielding materials were investigated, including $\mathrm{Pb}$, Pb-rubber, Reg. lead, Hx-lead, W-rubber, green Lite, and $\mathrm{Sn}-\mathrm{Ba}$ in the diagnostic imaging energy range. The samples with lower atomic numbers (Green Lite, $\mathrm{Hx}-\mathrm{Pb}, \mathrm{Sn}-$ $\mathrm{Ba}$ ) in most cases exhibited better attenuation than that of pure $\mathrm{Pb}$ protectors. W-rubber material had effective attenuation similar to $\mathrm{Pb}$ containing materials for 100 and $120 \mathrm{keV} .^{29}$ Also, a previously published study measured the attenuation effectiveness of some metal powders incorporated into polymer sheets such as $\mathrm{BaSO}_{4}, \mathrm{Gd}_{2} \mathrm{O}_{3}$, and $\mathrm{Bi}_{2} \mathrm{O}_{3}$ to introduce new radiation protection materials. $\mathrm{Gd}+\mathrm{Bi}$ and $\mathrm{Ba}+\mathrm{Bi}$ were prepared as bilayer shields in which the low atomic number layer was close to the source, and the attenuation effect of samples was examined. The minimum transmission was for $\mathrm{Gd}_{2} \mathrm{O}_{3}+\mathrm{Bi}_{2} \mathrm{O}_{3}$ sample and performed better than commercial $\mathrm{Pb}$ shielding. ${ }^{30}$

The obtained results in this study show that MNCs have better attenuation in comparison with single nanoparticle ones. They have better performance for widespread energy range. Our studied MNCs containing less toxic particles are suitable alternatives for toxic, uncomfortable and heavy traditional $\mathrm{Pb}$ garments. Also, due to MNCs' good mechanical properties, strength, lower weight, and flexibility, they can be manufactured in various shapes and sizes for different organs in IVR energy range and experimental evaluation of our findings is strongly recommended for their actual applications in medicine and industry.

\section{Conclusion}

In the current study, we designed and evaluated six nanoparticleloaded shielding materials using a silicon matrix. The attenuation efficiencies of all nano-based composites with different concentrations of 5, 15 and $30 \%$ and photon range of 10-140 keV were calculated using MCNPX MC code. Also, a novel idea of applying the MNCs capable of enhancing the attenuation of shielding material in a wide range of photon beams was tested. The results indicated that MNCs have better performance compared to single-nanoparticle composites. In order to enhance the efficiency of nanostructured composites we examined three MNC samples. The sample containing $\mathrm{Sm}_{2} \mathrm{O}_{3}$, $\mathrm{WO}_{3}$, and $\mathrm{Bi}_{2} \mathrm{O}_{3}$ exhibited greater shielding effectiveness in the photon energy range of $10-140 \mathrm{keV}$. Considering the potentials of multi-nanoparticle loaded composites, utilization of other polymers bases for special applications are suggested.

\section{Acknowledgments}

This project was performed as a part of MSc thesis of medical physics and funded by Medical Radiation Sciences Research Team of Tabriz University Of Medical Sciences.

\section{References}

1. Malekzadeh R, Mehnati P, Sooteh MY, Mesbahi A. Influence of the size of nano-and microparticles and photon energy on mass attenuation coefficients of bismuth-silicon shields in diagnostic radiology. Radiological Physics and Technology. 2019;12(3):325-334. https://doi.org/10.1007/s12194-019-00529-3

2. Mesbahi A, Verdipoor K, Zolfagharpour F, Alemi A. Investigation of fast neutron shielding properties of new polyurethane-based composites loaded with $\mathrm{B}_{4} \mathrm{C}, \mathrm{BeO}, \mathrm{WO}_{3}, \mathrm{ZnO}$, and $\mathrm{Gd}_{2} \mathrm{O}_{3}$ micro-and nanoparticles. Polish Journal of Medical Physics and Engineering. 2019;25(4):211-219. https://doi.org/10.2478/pjmpe-2019-0028

3. Kim J, Uhm YR, Byungchul L, et al. Radiation shielding members including nanoparticles as a radiation shielding material and method for preparing the same. In: Google Patents; 2012. 
4. Sayyed M. Investigation of shielding parameters for smart polymers. Chinese Journal of Physics. 2016;54(3):408-415. https://doi.org/10.1016/j.cjph.2016.05.002

5. Elmahroug Y, Tellili B, Souga C. Determination of shielding parameters for different types of resins. Annals of Nuclear Energy. 2014;63:619-623. https://doi.org/10.1016/j.anucene.2013.09.007

6. Singh VP, Badiger N. Shielding efficiency of lead borate and nickel borate glasses for gamma rays and neutrons. Glass Physics and Chemistry. 2015;41(3):276-283. https://doi.org/10.1134/S1087659615030177

7. Hassan H, Badran H, Aydarous A, Sharshar T. Studying the effect of nano lead compounds additives on the concrete shielding properties for $\gamma$-rays. Nuclear Instruments and Methods in Physics Research Section B: Beam Interactions with Materials and Atoms. 2015;360:8189. https://doi.org/10.1016/j.nimb.2015.07.126

8. Movahedi MM, Abdi A, Mehdizadeh A, et al. Novel paint design based on nanopowder to protection against X and gamma rays. Indian Journal of Nuclear Medicine: IJNM: the official journal of the Society of Nuclear Medicine, India. 2014;29(1):18. https://doi.org/10.4103/0972-3919.125763

9. Flora G, Gupta D, Tiwari A. Toxicity of lead: a review with recent updates. Interdisciplinary Toxicology. 2012;5(2):47. https://doi.org/10.2478/v10102-012-0009-2

10. McCaffrey J, Mainegra-Hing E, Shen H. Optimizing non-Pb radiation shielding materials using bilayers. Medical Physics. 2009;36(12):5586-5594. https://doi.org/10.1118/1.3260839

11. AbuAlRoos NJ, Amin NAB, Zainon R. Conventional and new lead-free radiation shielding materials for radiation protection in nuclear medicine: A review. Radiation Physics and Chemistry. 2019;165:108439. https://doi.org/10.1016/j.radphyschem.2019.108439

12. Dejangah M, Ghojavand M, Poursalehi R, Gholipour P. X-ray attenuation and mechanical properties of tungsten-silicone rubber nanocomposites. Materials Research Express. 2019;6(8):085045. https://doi.org/10.1088/2053-1591/ab1a89

13. Toyen D, Rittirong A, Poltabtim W, Saenboonruang K. Flexible, lead-free, gamma-shielding materials based on natural rubber/metal oxide composites. Iranian Polymer Journal. 2018;27(1):33-41. https://doi.org/10.1007/s13726-017-0584-3

14. Aghaz A, Faghihi R, Mortazavi S, Haghparast A, Mehdizadeh S, Sina S. Radiation attenuation properties of shields containing micro and Nano $\mathrm{WO}_{3}$ in diagnostic X-ray energy range. International Journal of Radiation Research. 2016;14(2):127. https://doi.org/10.18869/acadpub.ijrr.14.2.127

15. Shik NA, Gholamzadeh L. X-ray shielding performance of the EPVC composites with micro-or nanoparticles of $\mathrm{WO}_{3}, \mathrm{PbO}$ or $\mathrm{Bi}_{2} \mathrm{O}_{3}$. Applied Radiation and Isotopes. 2018;139:61-65. https://doi.org/10.1016/j.apradiso.2018.03.025

16. Kim J, Seo D, Lee BC, Seo YS, Miller WH. Nano-W Dispersed Gamma Radiation Shielding Materials. Advanced engineering materials. 2014;16(9):1083-1089. https://doi.org/10.1002/adem.201400127

17. Mansouri E, Mesbahi A, Malekzadeh R, Mansouri A. Shielding characteristics of nanocomposites for protection against X-and gamma rays in medical applications: effect of particle size, photon energy and nanoparticle concentration. Radiation and Environmental Biophysics. 2020:1-18. https://doi.org/10.1007/s00411-020-00865-8

18. Ma J, La LTB, Zaman I, et al. Fabrication, structure and properties of epoxy/metal nanocomposites. Macromolecular Materials and Engineering. 2011;296(5):465-474. https://doi.org/10.1002/mame.201000409

19. La LB, Leatherday $\mathrm{C}$, Qin $\mathrm{P}$, et al. The interaction between encapsulated $\mathrm{Gd}_{2} \mathrm{O}_{3}$ particles and polymeric matrix: The mechanism of fracture and X-ray attenuation properties. Colloids and Surfaces A: Physicochemical and Engineering Aspects. 2017;535:175-183. https://doi.org/10.1016/j.colsurfa.2017.09.038

20. Verdipoor K, Alemi A, Mesbahi A. Photon mass attenuation coefficients of a silicon resin loaded with $\mathrm{WO}_{3}, \mathrm{PbO}$ and $\mathrm{Bi}_{2} \mathrm{O}_{3} \mathrm{Micro}$ and Nano-particles for radiation shielding. Radiation Physics and Chemistry. 2018;147:85-90. https://doi.org/10.1016/j.radphyschem.2018.02.017

21. Wang P, Tang X, Chai H, Chen D, Qiu Y. Design, fabrication, and properties of a continuous carbon-fiber reinforced $\mathrm{Sm}_{2} \mathrm{O}_{3} / \mathrm{polyimide}$ gamma ray/neutron shielding material. Fusion Engineering and Design. 2015;101:218-225. https://doi.org/10.1016/j.fusengdes.2015.09.007

22. Hubbell JH, Seltzer SM. Tables of X-ray mass attenuation coefficients and mass energy-absorption coefficients $1 \mathrm{keV}$ to $20 \mathrm{MeV}$ for elements $Z=1$ to 92 and 48 additional substances of dosimetric interest. National Inst. of Standards and Technology-PL, Gaithersburg, MD (United States); 1995. https://doi.org/10.6028/NIST.IR.5632

23. Gerward L, Guilbert N, Jensen KB, Levring H. WinXCom-a program for calculating X-ray attenuation coefficients. Radiation Physics and Chemistry. 2004;71(3-4):653-654. https://doi.org/10.1016/j.radphyschem.2004.04.040

24. Yu D, Shu-Quan C, Hong-Xu Z, et al. Effects of WO3 particle size in WO3/epoxy resin radiation shielding material. Chinese Physics Letters. 2012;29(10):108102. https://doi.org/10.1088/0256-307X/29/10/108102

25. Nambiar S, Osei EK, Yeow JT. Polymer nanocomposite-based shielding against diagnostic X-rays. Journal of Applied Polymer Science. 2013;127(6):4939-4946. https://doi.org/10.1002/app.37980 
26. Atashi P, Rahmani S, Ahadi B, Rahmati A. Efficient, flexible and lead-free composite based on room temperature vulcanizing silicone rubber/W/Bi ${ }_{2} \mathrm{O}_{3}$ for gamma ray shielding application. Journal of Materials Science: Materials in Electronics. 2018;29(14):1230612322. https://doi.org/10.1007/s10854-018-9344-1

27. Akbay İK, Güngör A, Özdemir T. Optimization of the vulcanization parameters for ethylene-propylene-diene termonomer (EPDM)/ground waste tyre composite using response surface methodology. Polymer Bulletin. 2017;74(12):5095-5109. https://doi.org/10.1007/s00289-017-2001-7

28. Sonsilphong A, Wongkasem N. Light-weight radiation protection by non-lead materials in X-ray regimes. Paper presented at: 2014 International Conference on Electromagnetics in Advanced Applications (ICEAA)2014. https://doi.org/10.1109/ICEAA.2014.6903939

29. McCaffrey J, Shen H, Downton B, Mainegra-Hing E. Radiation attenuation by lead and nonlead materials used in radiation shielding garments. Medical Physics. 2007;34(2):530-537. https://doi.org/10.1118/1.2426404

30. McCaffrey J, Tessier F, Shen H. Radiation shielding materials and radiation scatter effects for interventional radiology (IR) physicians. Medical Physics. 2012;39(7Part1):4537-4546. https://doi.org/10.1118/1.4730504 